\title{
Transplantation of Human Fetal Mesencephalic Tissue in Caudate Nucleus as a Treatment for Parkinson's Disease. Long- Term Follow-Up
}

\author{
H. Molina, R. Quiñones, L. Alvarez, C. Suărez, I. Ortega, J.L. Muñoz, M. Rachid, \\ O. Torres, M.J. Rojas, M. León, J.C. García, R. Macías, L. Lorigados, \\ T. Perry, J. Piedra, C. González, F. Araújo and O. Hernández
}

Centro Iberolatinoamericano de Transplante y Regeneración del Sistema Nervioso, Avenida 25 \# 15805, entre 158 y 160, Playa, Ciudad de La Habana, Cuba

Based on two primary motivating factors, namely the successful functional grafting of embryonic nervous tissue to brain in animal models of neurological disorders, and the need of new therapeutic alternatives for many patients with severe Parkinson's disease, a Neurotransplantation Program was initiated in Cuba in 1984.

From April to December 1987, after carrying out rodent neurografting studies, we performed adrenal medulla autotransplantation on three parkinsonian patients. From January 1988 to April 1990, thirty patients with advanced Parkinson's disease suffering from severe motor complications associated with L-Dopa therapy underwent fetal ventral mesencephalic tissue transplantation in the caudate nucleus, using an open microsurgical procedure.

The series of patients had a median age of 45 years (range 36-55); the evolution time of the disease was 9 years (4-18), and the duration of pre-operative L-Dopa treatment ranged from 1 to 12 years (median 7 years).

The clinical evaluations, based on international rating systems, were performed before the operation and after 15 days, $1,3,6,12,18$, $24,30,36,48$ and 52 months.

Several solid fragments $(2-8$, mean $=6)$ of ventral mesencephalic tissue from fetuses aged 6-12 weeks were implanted on the head of the caudate nucleus using an open microsurgical transfrontal approach to the lateral ventricle. The mean time between abortion and implantation was 45 minutes.

The evolution of the neurological condition of the thirty patients, assessed during a long period of follow-up, can be summarized as follows:
- Significant improvements in motor complications associated with L-Dopa therapy, including reductions in both the daily "off" time from $56 \%$ before surgery to $2 \% 42$ months after transplantation, and the number of daily "off" periods from 5.1 before to 1.5 after grafting.

- Better response to L-Dopa therapy in the post-surgical stage.

- Reduction in the post-operative daily L-Dopa requirements from $984 \mathrm{mg} / 24 \mathrm{~h}$ before to 399 $\mathrm{mg} / 24 \mathrm{~h} 42$ months after operation.

- Progressive improvement of the neurological performance demonstrated by UPDRS scores. This improvement was statistically significant from 3 to 36 months after surgery (Fig. 1).

- The "off" quality improvement in the postoperative stage ranged from $46.3 \%$ in the $3 \mathrm{rd}$ month to $49.6 \%$ in the 42 nd.

- Progressive alleviation of the major symptoms of Parkinson's disease, most pronounced contralaterally to the graft, that contributed to the enhancement of the patient's quality of life.

The results of this study demonstrated that transplantation of fetal mesencephalon in caudate nucleus can significantly improve the neurological condition of selected parkinsonian patients with severe clinical fluctuations as complications of L-Dopa therapy for a long period after surgery. 


\section{Clinical Evolution (UPDRS)}

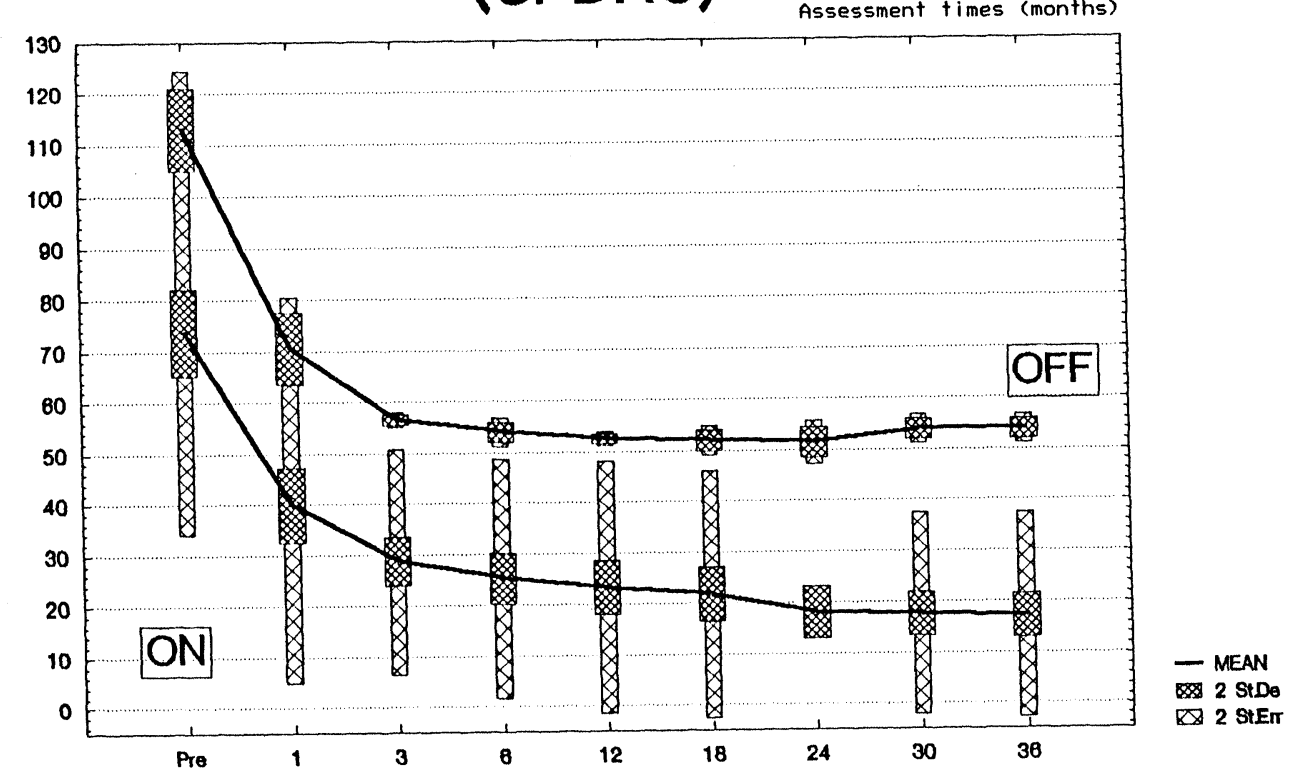

Fig. 1: Clinical evolution from 30 to 40 days before to 36 months after transplantation.

Progressive clinical improvement statistically significant from 3 to 36 months after grafting $(P \leq 0.01)$ (Wilcoxon matched pairs test). 

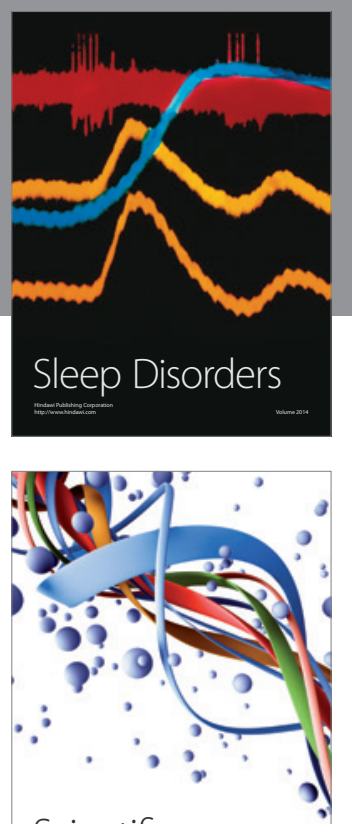

Scientifica
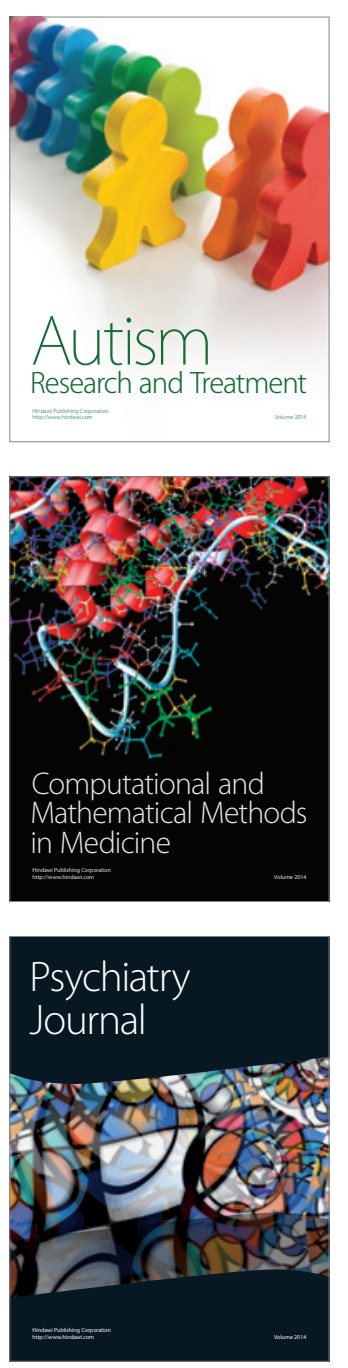
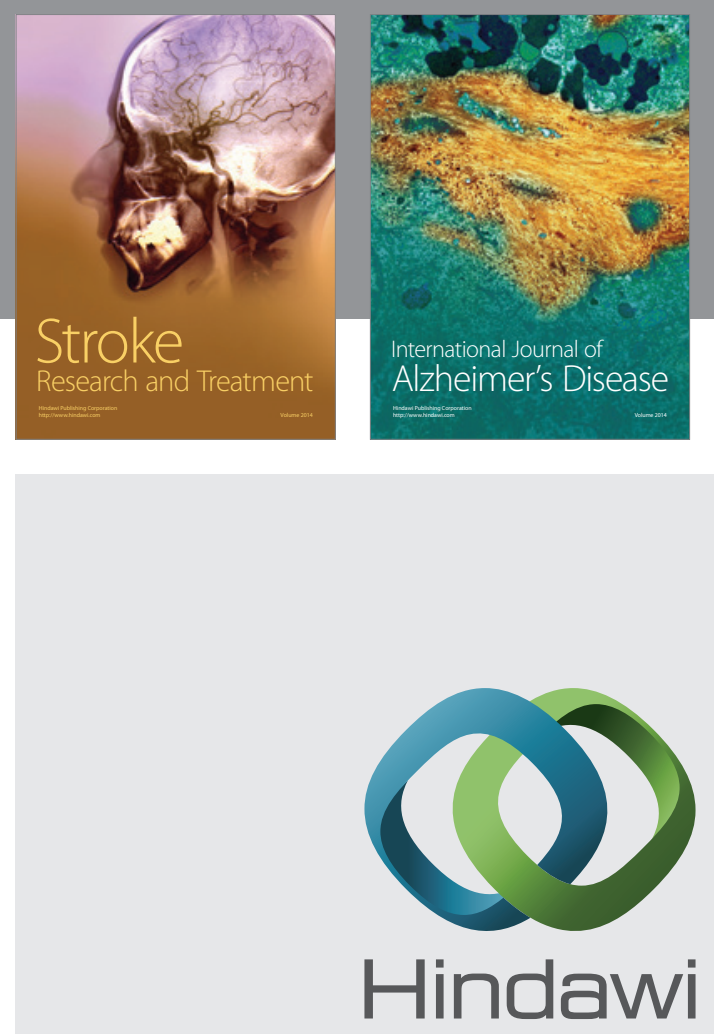

Submit your manuscripts at

http://www.hindawi.com
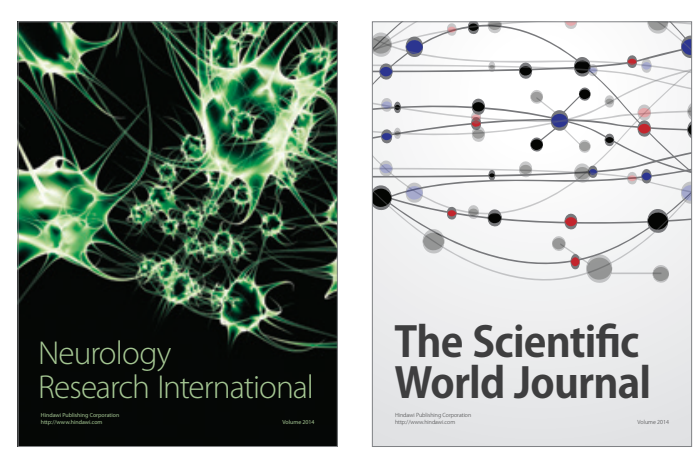

The Scientific World Journal

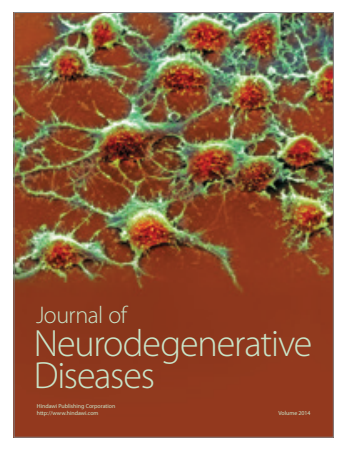

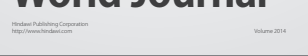

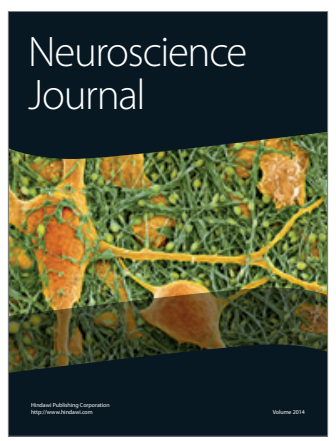

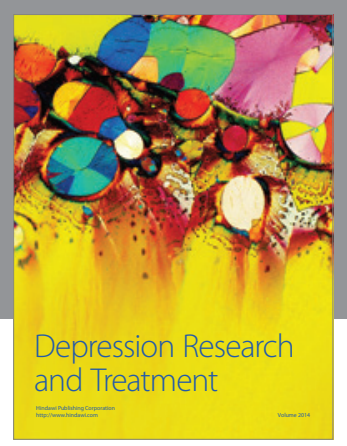
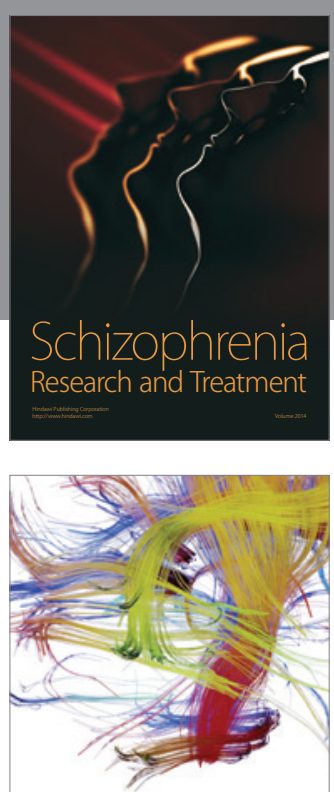

Brain Science

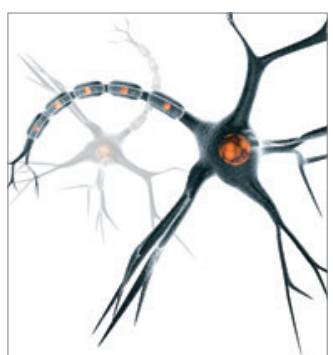

Neural Plasticity
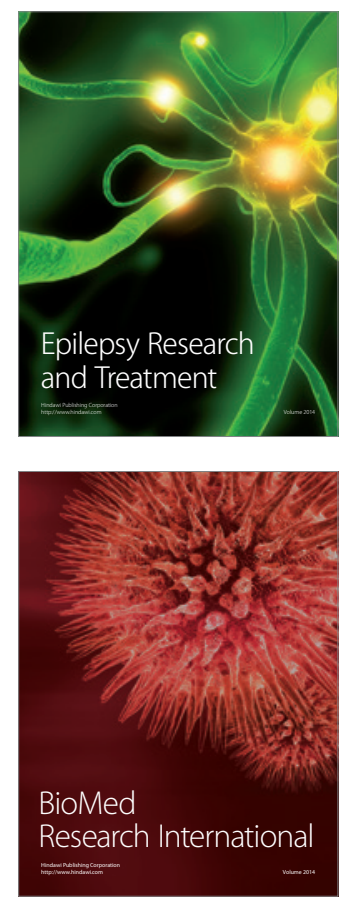

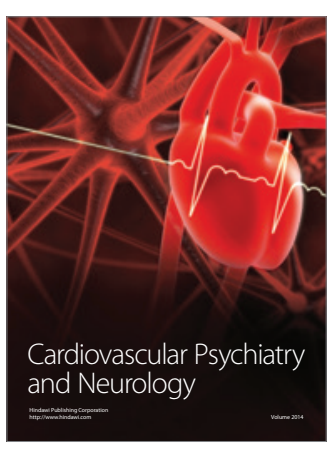

Parkinson's

Disease
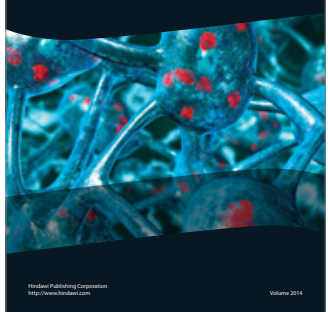